\title{
OS GOVERNOS DO IMPÉRIO: VICE-REIS. GOVERNADORES E CAPITÃES-MORES NO MUNDO PORTUGUÊS (SÉCULOS XVI-XIX) - GOVERNOS E PRÁTICAS GOVERNATIVAS
}

ARTHUR CURVELO *

INSTITUTO DE ESTUDOS MEDIEVAIS DA UNIVERSIDADE NOVA DE LISBOA

LISBOA - PORTUGAL

THIARA BERNARDO DUTRA "

UNIVERSIDADE FEDERAL DO ESPÍRITO SANTO

VITÓRIA - ESPÍRITO SANTO - BRASIL

\begin{abstract}
"A Câmara e a Misericórdia podem ser descritas, com algum exagero, como os pilares gêmeos da sociedade colonial portuguesa do Maranhão até Macau. Elas garantiam uma continuidade que os governadores, os bispos e os magistrados transitórios não podiam assegurar." (BOXER, 2002, [1969], p. 286)
\end{abstract}

Talvez esta seja uma das citações mais difundidas da obra do historiador Charles Ralph Boxer, sobretudo em estudos centrados nas estruturas político-administrativas do mundo português, sendo encontrada, com ligeiras variações, tanto em Portuguese Society in the tropics ${ }^{1}$, publicada em 1965, quanto em The Portuguese Seaborn Empire, publicada pela primeira vez em $1969^{2}$. Para Boxer, as Câmaras serviriam de espaço privilegiado para a perpetuação e representação política de elites locais, oferecendo "um elemento de estabilidade e continuidade" capaz de sustentar o império português na sua dispersão, e que era, até certo ponto, contraposto à transitoriedade que caracterizava os mandatos de vice-reis e governadores trocados no posto, idealmente, de três em três anos ${ }^{3}$.

Não resta dúvida de que a presença e atuação das Câmaras foi tanto essencial para contornar a dispersão territorial das conquistas, garantindo o enraizamento dos portugueses e de seus descendentes nesses espaços, quanto para dar voz e legitimar a posição dos grupos sociais que disputavam o poder local, contribuindo para amortizar as

\footnotetext{
* Doutor em História pelo Programa Interuniversitário de Doutoramento em História: mudança e continuidade num mundo global (PIUDHist) e Investigador integrado no Instituto de Estudos Medievais da Universidade Nova de Lisboa (IEM), atualmente bolsista de investigação no projeto VINCULUM: Entailing Perpetuity: Family, power identity. The social agency of a corporate body (Southern Europe, 14th-17th centuries) financiado pelo European Research Council (ERC), grant agreement No. 819734. E-mail: arthurasccurvelo@gmail.com.

** Doutoranda em História pelo Programa de Pós-Graduação em História da Universidade Federal do Espírito Santo (UFES), com bolsa FAPES. Pesquisadora do Laboratório de História, Poder e Linguagens da UFES. E-mail: thiarabernardo@hotmail.com. ${ }^{1}$ BOXER, Charles R. Portuguese society in tropics: the municipal councils of Goa, Macao, Bahia and Luanda (1510-1800). Madison: The University of Wisconsin Press/ Madison and Milwaukee, 1965.

${ }^{2}$ BOXER, Charles R. O império Marítimo Português (1415-1825). Tradução de Anna Olga de Barros Barreto. São Paulo: Companhia das Letras, 2002.

3 Tradução livre e adaptada do seguinte excerto: "Another advantage of the Camaras, from the crown's point of view, was that they provided an element of stability and continuity in cities where the viceroys and governors were usually relieved every three years". BOXER, 1965, p. 145.
} 
tensões políticas no interior do império. Porém, cada vez mais contribuições, sobretudo nas últimas duas décadas, têm demonstrado que vice-reis e governadores desempenharam um papel de relevo enquanto intermediários entre a administração central da monarquia e os diferentes territórios, servindo eles também de pilares do império. Os Governos, talvez mais do que os próprios governadores, ofereciam outros elementos de estabilidade e de continuidade essenciais à sobrevivência da monarquia portuguesa, ao passo que a transitoriedade dos homens poderia ser contornada ou, no limite, atenuada de diferentes maneiras. As secretarias de governo, por exemplo, através da ação e da experiência dos secretários, materializavam e davam forma ao corpo institucional dos Governos, servindo também como repositórios da memória governativa, elemento essencial para compensar a concessão precária, e trienal, do posto de governador ${ }^{4}$. A circulação destes homens por diferentes territórios poderia também levar à circulação, transmissão e adaptação de práticas governativas no interior do império ${ }^{5}$.

As entradas e a participação dos vice-reis e governadores nos rituais públicos do mundo português figuram como oportunidades de exteriorização e de demarcação das hierarquias políticas e sociais, mas, principalmente, da comunicação ritual da autoridade régia no espaço das conquistas. Não nos esqueçamos que a manutenção de uma corte para o Vice-Reis em Goa com o devido fausto e aparato era fundamental para assegurar a posição e fundar uma imagem de respeitabilidade da Coroa portuguesa perante os reinos vizinhos ${ }^{6}$.

Ao considerarmos este como um "império de papel", empregando aqui uma feliz expressão de António Manuel Hespanha ${ }^{7}$, vemos, por exemplo, que os governadores e vice-reis tiveram um destacado protagonismo ao garantir a continuidade das comunicações entre os diferentes territórios. Uma demonstração consistente dessa tendência foi apresentada por recentes projetos de investigação que demonstraram, com base numa amostra de grande escopo geográfico, que os governadores e vice-reis

\footnotetext{
${ }^{4}$ PUNTONI, Pedro.Bernardo Vieira Ravasco, secretário do Estado do Brasil: poder e elites na Bahia do século XVII. In: FERLINI, Vera Lúcia \& BICALHO, Maria Fernanda (Org.) Modos de Governar. São Paulo: Alameda, 2005. p. 157-179.

${ }^{5}$ GOUVÊA, Maria de Fátima Silva. "Redes governativas portuguesas e centralidades régias no mundo português, c. 1680-1730". GOUVÊA, Maria de Fátima, FRAGOSO, João (Org.) Na trama das redes: política e negócios no mundo português, séculos XVIXVIII. Rio de Janeiro: Civilização Brasileira, 2010.

${ }^{6}$ SANTOS, Catarina Madeira. "Goa é a chave de toda a índia": perfil político da capital do Estado da Índia. Lisboa: CNCDP, 1999.

${ }^{7}$ HESPANHA, A. M. As vésperas do Leviathan: instituições e poder político. Portugal, séc. XVII, Coimbra: Livraria Almedina, 1994, p. 291
} 
respondem por cerca de $25 \%$ das comunicações político-administrativas trocadas entre Lisboa e as capitanias principais da América Portuguesa entre os anos de 1642 e $1808 .^{8}$ Estes dados, apontam para o relevo destes agentes na produção do conhecimento e do saber político trocado entre as conquistas e o centro da monarquia, mas também são particularmente reveladores da frequência com que opinavam sobre as comunicações veiculadas por outros poderes ao rei, por meio de petições, requerimentos e representações, o que lhes dava oportunidade para influenciar nos processos de decisão que tinham lugar na Corte ${ }^{9}$.

Em virtude do lugar de importância que ocupavam na arquitetura políticoadministrativa e da interferência que, muitas vezes, tentavam exercer nos cenários políticos locais, com maior ou menor sucesso, os governadores e vice-reis representam os principais alvos de queixa por parte dos poderes locais. Juntamente às reclamações nascidas dos excessos ou conflitos de jurisdição, acumulam-se denúncias que perpassam vários mandatos, no tempo e no espaço, contra os atos de ilicitude e descaminho praticados pelos governadores no desempenho de suas funções. Não por acaso o deputado Manuel Fernandes Tomás atacou-os tão ferozmente no manifesto intitulado $O$ Lutero, publicado em Lisboa em 1822, referindo-se aos governos do Brasil, na iminência de sua irreversível emancipação, como "governos, que se davam aos senhores de casas arruinadas para irem lá desempenhar-se, governando como Verres ${ }^{10}$ ", e ainda "estes lugares em que eram providos os que davam mais dinheiro: estas administrações, que eram confiadas só a quem fazia uma obrigação de entregar metade do rendimento ao padrinho, que o despachava" no ato da nomeação ${ }^{11}$.

Esta segunda parte do dossiê Os Governos do império: governadores, capitãesmores e vice-reis (séculos XVI-XIX) reúne onze artigos escritos por historiadoras e historiadores que, para além da análise das trajetórias e dos mandatos individuais que

\footnotetext{
${ }^{8}$ COSENTINO, Francisco et al. "Governadores reinóis e ultramarinos". In: FRAGOSO, J.; MONTEIRO, N. (Org.). Um reino e suas repúblicas no Atlântico: comunicações políticas entre Portugal, Brasil e Angola nos séculos XVII e XVIII. 1a edição. Rio de Janeiro: Civilização Brasileira, 2017, p. 302.

${ }^{9}$ CURVELO, A. Governar Pernambuco e as "capitanias anexas": o perfil de recrutamento, a comunicação política e as jurisdições dos governadores da capitania de Pernambuco (c. 1654-c. 1756). Tese (Doutorado em História), Programa Interuniversitário de Doutoramento em História, Universidade de Lisboa, 2019, p. 294-313.

${ }^{10}$ Caio Verres, governador da Sicília entre 73 e 71 A.C, foi processado por ninguém menos que Cícero como um dos piores governadores daquela província. Cícero publicou os discursos de acusação em uma obra que se intitula In Verrem. Obra disponível em: https://www.thelatinlibrary.com/cicero/ver1.shtml

${ }^{11}$ CARDOSO, José Luís (ed.). Manuel Fernandes Tomás: escritos políticos e discursos parlamentares (1820-1822). Lisboa: Imprensa de Ciências Sociais, 2020. p. 192-193.
} 
marcam a primeira parte, procuram observar os governadores numa perspectiva diacrônica, quer através da análise dos estatutos e da estrutura político-administrativa dos diferentes Governos, quer através de questões e problemas gerais que perpassam os mandatos de diferentes governadores, bem como da interação entre aqueles que ocupam postos em diferentes capitanias.

$\mathrm{O}$ artigo de Hugo André Flores de Araújo, “Com cartas para todas as câmaras deste Estado: a comunicação política entre o governo-geral e as câmaras do Estado do Brasil (1642-1682)" oferece uma contribuição rica e inovadora para o estudo dos governadores-gerais enquanto ativos protagonistas nos circuitos de comunicação política da monarquia portuguesa. No artigo, este autor se debruça sobre os fluxos de comunicação que circulavam no interior do Estado do Brasil, tema ainda pouco explorado pela historiografia, apresentando um sólido conjunto de dados que desvela a heterogeneidade dos padrões de contato, relacionamento e interação entre o GovernoGeral e as câmaras das diferentes capitanias da América Lusa, observando como este circuito promove a interligação entre arenas de governo local e central, estabelecendo, materialmente, a governabilidade numa escala regional.

Em "Os governos interinos no Império Português (séculos XVII-XVIII)", Naira Maria Mota Bezerra aborda um tema inovador e que só recentemente tem recebido atenção sistemática da historiografia: os governos provisórios. Nesse artigo, a autora propõe uma reflexão tipológica acerca das circunstâncias emergenciais ou intencionais que levavam à vacância no posto de governador e identifica padrões de ocupação dos Governos, por poderes unipessoais ou colegiados. Demonstra-se que o tempo de exercício, a existência de normas para reger a sucessão dos governadores titulares e o respaldo da Coroa à constituição dos governos interinos poderiam representar oportunidades para grupos políticos locais e outras autoridades, civis ou eclesiásticas, afirmarem os seus próprios interesses.

A Coroa nem sempre conseguia intervir na nomeação de todos os governos do império, existindo também governadores e capitães-mores nos senhorios jurisdicionais delegados à jurisdição dos donatários. Com efeito, os artigos de José Damião Rodrigues, "Quando não assiste nela o conde de Vila Franca: os governadores da Ilha de S. Miguel (Açores) nos séculos XVII e XVIII" e de Luciana de Carvalho Barbalho Velez, "A 
administração dos Marqueses de Cascais em Itamaracá: capitães-mores e procuradores do donatário (1692-1763)", abordam os governos estabelecidos em terras de donatários a partir de territórios com diferentes configurações geográficas e sociais, a saber, numa das principais ilhas do arquipélago dos Açores e numa capitania secundária dentre as capitanias do Norte do Estado do Brasil. Ambos os artigos abordam a natureza dos cargos de governador e capitão-mor, respectivamente, analisando não só perfis de recrutamento, mas demonstrando a complexidade dos processos de seleção destes homens, inicialmente designados para substituir os donatários em momentos de ausência, e que passam, posteriormente, a uma nomeação regular destinada a suprir o absenteísmo quase permanente dos mesmos, no caso açoriano, e total, no caso de Itamaracá. Os textos mostram contrastes visíveis entre os dois governos. Se José Damião Rodrigues destaca que a ocupação do posto de governador em São Miguel traria ao ocupante do cargo alguma dignidade, abrindo portas a outras posições de importância dentro do império, inclusive a governos de outros territórios, Luciana Barbalho Velez demonstra que os capitães-mores em Itamaracá eram vistos e atuavam como meros procuradores dos donatários, espremidos em meio aos conflitos de jurisdição entre os governos de Pernambuco e da Bahia. Esse é, aliás, outro aspecto de contraste, pois o quadro de razoável estabilidade e cooperação entre os governadores de São Miguel e os poderes locais, difere do clima de constante atrito vivido entre os capitães-mores de Itamaracá e os poderes locais da capitania, e entre os capitães e o governador de Pernambuco.

O artigo de Augusto da Silva, "Capitania-mor de Sergipe del Rei e governo da Ilha de Santa Catarina: estatutos, jurisdições e hierarquias" oferece uma comparação entre os governos de duas capitanias secundárias na América portuguesa, ambas fundadas como capitanias régias, subordinadas ao governo de capitanias principais e cuja formação tem vários pontos em comum. No entanto, o autor analisa as diferenças estruturais na composição dos poderes existentes em cada capitania, assinalando, por exemplo, uma mais forte presença militar em Santa Catarina do que em Sergipe, assim como diferenças de estatuto e formas de tratamento dos governantes de ambas, sendo os de Sergipe tratados por "capitães-mores" e os de Santa Catarina como "governadores", a que correspondem também diferenças de soldo, e variações de vocabulário numa sociedade de Antigo Regime não são meramente aleatórias, como bem demonstra o autor. 
Se a concessão de títulos e estatutos representa também uma modalidade de demarcar as diferenças e de estabelecer hierarquias neste período, a forma como se designavam os homens que ocupavam os diferentes governos era especialmente relevante, representando, em si, um objeto de estudo. A pretensão dos capitães-mores da Paraíba ao título de "governador e capitão-general” é analisada por Marcos Arthur Viana da Fonseca no artigo "Governadores e capitães-generais: as ambições políticas dos capitães-mores da Paraíba (primeira metade do século XVIII)”. O autor demonstra que, mais do que uma ambição pessoal dos homens que ocuparam o posto de capitão-mor, este era um ato de resistência dos capitães-mores, cultivado no imaginário político local, partilhado, inclusive pela nobreza da terra desta capitania, e que pretendia afirmar a posição da Paraíba no conjunto das outras Capitanias do Norte, dando-lhe um estatuto de importância equivalente ao das capitanias principais, como a sua vizinha Pernambuco, a cujo Governo seria subordinada em 1755.

O valor do soldo, como demonstra Augusto Silva, é também um fator relevante para se perceber a diferença de estatuto entre as conquistas. Porém, os ganhos materiais dos governadores em exercício não se limitavam ao soldo recebido da Real Fazenda. Com isso, o uso do cargo de governador para satisfação de interesses pessoais, é tema do artigo "Para além do soldo: práticas comerciais e formas de ganho dos governantes das capitanias do norte (séculos XVII - XVIII)", de Leonardo Paiva de Oliveira, em que são analisadas as estratégias de que dispunham os governadores de capitania para a obtenção de recursos extraordinários ou, como denomina o autor, ganhos. Embasado em recente historiografia sobre a corrupção no período moderno, o artigo analisa tanto as formas utilizadas pelos governadores, especialmente, de Pernambuco, da Paraíba e do Ceará, de potencializar seus ganhos ao se imiscuir em atividades comerciais, por exemplo, quanto a reação dos demais agentes da capitania, entre os quais, a própria Coroa, no tocante a essa prática.

Como já referido quando aludimos às palavras de Fernandes Tomás, ganhos ilícitos e envolvimento direto com o comércio são motivos que levam, frequentemente, à formulação de queixas contra os governantes das conquistas. Este tema é desenvolvido em maior profundidade no artigo de Lana Camila Gomes de Araújo e George Félix Cabral de Souza, "Imbróglios do poder: manifestações dos administrados sobre os 
governadores da Capitania da Paraíba na primeira metade do século XVIII", no qual os autores propõem uma reflexão acerca dos motivos que levavam os súditos desta capitania a manifestar-se contrária ou favoravelmente aos governadores, criando imagens de bom e de mau governo. Os autores demonstram que a capacidade de adaptação dos governadores ao cenário político, onde era imperativo tecer pactos e alianças com as elites locais, era determinante para a formulação de queixas ou manifestos de aprovação, quase sempre vistos com desconfiança por parte da Coroa portuguesa.

Contribuindo ainda para o debate acerca da anexação ou subordinação das Capitanias do Norte ao Governo de Pernambuco, o artigo de Tyego Franklim da Silva, "Jurisdições e mudanças de subordinação na administração da Capitania do Rio Grande: análise das correspondências entre autoridades coloniais (1695-1705)", analisa as relações entre três diferentes governos, a saber, os do Rio Grande, o de Pernambuco e o Governo-Geral na virada do século XVII para o XVIII, quando a Guerra do Açu acendeu disputas por jurisdição particularmente intensas entre esses três Governos cujo mote principal era a necessidade de subordinar a capitania do Rio Grande ao Governo de Pernambuco.

Outro artigo que aborda conexões entre diferentes geografias do Império português é "Uma história de amor e ódio: a administração régia em Cabo Verde e a Companhia Geral do Grão-Pará e Maranhão”, de Diego de Cambraia Martins. Nele, o autor discute a relação estabelecida entre a companhia de comércio e os oficiais régios, mais especificamente, governadores e ouvidores, residentes no arquipélago. A fim de analisar a percepção dos funcionários da alta administração régia cabo-verdiana sobre a atuação da Companhia Geral do Grão-Pará e Maranhão, o autor desvela a conflituosa relação que envolvia não só os interesses desses oficiais régios e dos agentes da empresa monopolista, como também dos habitantes da ilha.

Por fim, Adriano Comissoli e Leandro Rosa de Oliveira em "Necessita aquela província, não só de governador, mas de coronel de dragões: os comandantes de fronteira portugueses e o governo da capitania do Rio Grande de São Pedro, século XVIII”, oferece-nos uma relevante contribuição à história político-administrativa da América Portuguesa, sobretudo no que tange às especificidades de uma região de fronteira. Os autores analisam como a criação de um posto identificado apenas nessa 
região, qual seja, o de Comandante da Fronteira, responde aos desafios da territorialização do poder na capitania do Rio Grande de São Pedro entre os séculos XVIII e XIX. Talvez seja este o equivalente funcional mais próximo, em terras lusas, dos tenientes de gobernador, do mundo hispânico, na medida em que estes homens atuam como subordinados diretos dos governadores em espaços onde estes não podem estar sempre presentes, compartilhando, com isso, o esforço de organização e vigilância do território.

Com efeito, esta segunda parte do dossiê Os Governos do Império reúne historiadoras e historiadores em diferentes estágios de formação, unindo os mais jovens aos mais experientes, cujas contribuições convidam os leitores e as leitoras da Revista Ágora a refletir sobre as práticas de perpetuação do poder no tempo e no espaço, vistas através dos Governos e dos governadores. A quantidade de artigos reunidos nas duas partes do dossiê é reveladora da atenção que os historiadores têm dado à temática na última década e testemunha a vitalidade que os estudos sobre o poder e administração continuam a ter nesta época em que é tão necessário refletir sobre a formação política brasileira.

\section{REFERÊNCIAS}

BOXER, Charles R. Portuguese society in tropics: the municipal councils of Goa, Macao, Bahia and Luanda (1510-1800). Madison: The University of Wisconsin Press/ Madison and Milwaukee, 1965.

BOXER, Charles R. O Império Marítimo Português (1415-1825). Tradução de Anna Olga de Barros Barreto. São Paulo: Companhia das Letras, 2002.

CARDOSO, José Luís (ed.). Manuel Fernandes Tomás: escritos políticos e discursos parlamentares (1820-1822). Lisboa: Imprensa de Ciências Sociais, 2020.

COSENTINO, Francisco et al. "Governadores reinóis e ultramarinos". In: FRAGOSO, J.; MONTEIRO, N. (Org.). Um reino e suas repúblicas no Atlântico: comunicações políticas entre Portugal, Brasil e Angola nos séculos XVII e XVIII. 1a edição. Rio de Janeiro: Civilização Brasileira, 2017.

CURVELO, A. Governar Pernambuco e as "capitanias anexas": o perfil de recrutamento, a comunicação política e as jurisdições dos governadores da capitania de Pernambuco (c. 1654-c. 1756). Tese (Doutorado em História), Programa Interuniversitário de Doutoramento em História, Universidade de Lisboa, 2019. 
GOUVÊA, Maria de Fátima Silva. "Redes governativas portuguesas e centralidades régias no mundo português, c. 1680-1730". GOUVÊA, Maria de Fátima, FRAGOSO, João (orgs.) Na trama das redes: política e negócios no mundo português, séculos XVIXVIII. Rio de Janeiro: Civilização Brasileira, 2010

HESPANHA, A. M. As vésperas do Leviathan: instituições e poder político. Portugal, séc. XVII, Coimbra: Livraria Almedina, 1994.

PUNTONI, Pedro. Bernardo Vieira Ravasco, secretário do Estado do Brasil: poder e elites na Bahia do século XVII. In: FERLINI, Vera Lúcia; BICALHO, Maria Fernanda (Org.). Modos de Governar. São Paulo: Alameda, 2005.

SANTOS, Catarina Madeira. "Goa é a chave de toda a índia": perfil político da capital do Estado da Índia. Lisboa: CNCDP, 1999. 